\title{
Molecular characterization of cyclophilin A-like protein from Piriformospora indica for its potential role to abiotic stress tolerance in $E$. coli
}

\author{
Dipesh Kumar Trivedi ${ }^{1}$, Mohammed Wahid Ansari ${ }^{1}$, Tanima Dutta ${ }^{2}$, Prabhjeet Singh ${ }^{2}$ and Narendra Tuteja ${ }^{\text {* }}$
}

\begin{abstract}
Background: Cyclophilins (CyP), conserved in all genera, are known to have regulatory responses of various cellular processes including stress tolerance. Interestingly, CyP has a crucial role as peptidyl-prolyl cis-trans isomerases (PPlases). Our earlier in silico based approach resulted into the identification of cyclophilin family from rice, Arabidopsis and yeast. In our recent report, we discovered a new OsCYP-25 from rice. Here, we identified a novel cyclophylin A-like protein (PiCyP) from Piriformospora indica which is responsible for abiotic stress tolerance in E. coli.

Results: Cyclophylin A-like protein (CyPA) (accession number GQ214003) was selected from cDNA library. The genomic organization CyPA revealed a 1304 bp of CyPA in P. indica genome, showing 10 exons and 9 introns. Further, CyPA was evident in PCR with gDNA and CDNA and Southern blot analysis. The phylogenetic examination of CyPA of $P$. indica showed that it is closed to human cyclophilin. The uniqueness of PiCyPA protein was apparent in western blot study. Kinetics of purified PiCyPA protein for its PPlas activity was determined via first order rate constant $\left(0.104 \mathrm{~s}^{-1}\right)$ in the presence of $1 \mu \mathrm{g}$ of PiCyPA, with increasing PiCyPA concentration, in the presence of cyclosporin A (CSA) and the inhibition constant ( $4.435 \mathrm{nM}$ ) of CSA for inhibition of PiCyPA. The differential response of E. coli harbouring pET28a-PiCypA was observed for their different degree of tolerance to different abiotic stresses as compared to empty pET28a vector.

Conclusions: Overexpression of PiCyPA protein E. coli cells confer enhanced tolerance to wide range of abiotic stresses. Thus, this study provides the significance of PiCypA as a molecular chaperone which advanced cellular stress responses of $E$. coli cells under adverse conditions, and it, furthermore, confirms the mounting the sustainability of E. coli for exploitation in recombinant proteins production. Additionally, the PiCyPA gene cooperates substantial functions in cellular network of stress tolerance mechanism, essentially required for various developmental stages, and might be a potential paramount candidate for crop improvement and its sustainable production under adverse conditions.
\end{abstract}

\section{Background}

Worldwide salinity problems affect approximately 3,230, $000 \mathrm{~km}^{2}$ area of land that threatens plant growth and agricultural productivity [1]. A plant-root-colonizing basidiomycete fungus Piriformospora indica (P.indica) was discovered in the Indian Thar desert that has shown to provide strong growth-promoting activity during its symbiosis with a broad spectrum of plants [2]. Salt stress studies have indicated promising effect of $P$. indica in

\footnotetext{
* Correspondence: narendra@icgeb.res.in

${ }^{1}$ Plant Molecular Biology Group, International Centre for Genetic Engineering and Biotechnology (ICGEB), Aruna Asaf Ali Marg, New Delhi 110 067, India Full list of author information is available at the end of the article
}

barley [3]. It was shown that $P$. indica leads to early flowering, higher biomass and altered secondary metabolites of the medicinal plant, Coleus forskohlii [4]. Cyclophilins (CуP) are widely distributed and abundantly found proteins in eukaryotic and prokaryotic systems, which present in cytosol as well as nucleus [5]. Extensive studies of various model organisms have suggested that cyclophilins are involved directly or indirectly in wide range of cellular processes including cell division [6], transcriptional regulation [7], protein trafficking [8], cell signaling [9,10], pre-mRNA splicing [11], molecular chaperone [12,13] and stress tolerance $[14,15]$. They are known to possess enzymatic activity in the form of peptidyl-prolyl cis-trans isomerase (PPIase) catalysis, a reaction thought to be involved in the

\section{Biomed Central}


late stages of protein folding [16,17]. Molecular mechanism of PPIase activity in human T-cells has already been characterized structurally as well as biochemically [18]. CyPA from human T-cell has high affinity for the immune-suppressive drug Cyclosporin A (CsA) [19] and its PPIase activity can be totally inhibited by CsA. CyPA has been shown to interact with Calcineurin directly and modulating the $\mathrm{Ca}^{+2}$ signaling in human $\mathrm{T}$ cells [20], which is a primary signaling molecule in majority of the cellular events and responses. In plants, CyPA was involved in signal transduction mechanism of regulation of various abiotic stresses via phosphoprotein cascade, $\mathrm{Ca}^{+2}$ and other secondary signaling molecules [21]. In our recent report, we identified a new class of cyclophilin OsCyP-25 (LOC_Os09 g39780) from rice (Oryza sativa L.), which was upregulated in response to different abiotic stresses viz., salinity, cold, heat and drought [22]. In the present study, we have shown the cloning, expression, purification and crystallization of CyPA homologue from Piriformospora indica (PiCyPA) to understand the molecular mechanism(s) involved cell signalling network during various stress response and its potential role in providing stress tolerance both in eukaryotes and prokaryotes.

\section{Results}

Identification, genomic organization, isolation and confirmation of a novel cyclophilin from $P$. indica Cyclophylin A-like protein (CyPA) (accession number GQ 214003) was selected from cDNA library for further study. Additionally, the genomic organization $C y P A$ gene has been identified by using genomic sequence available on NCBI (http://www.ncbi.nlm.nih.gov) which shows that CyPA gene (1304 bp) in $P$. indica genome revealed 10 exons (ranged from 12-135 bp) and 9 introns (varied from 4-178 bp). Introns spliced out sequence i.e. exons sequence which stick together leading to the formation of CyPA gene (535 bp) (Figure 1A). Further, genomic organization of $C y P A$ gene was evident from PCR amplification with $P$. indica gDNA and cDNA as a template using primers (forward: $5^{\circ}$ CTC GAGCATATGTCCCAGCCCAACGTCTACTTTG 3` and reverse: 5`-GAATTCTTAGACAGTGCCAGACGCAGTA ATCTTG 3'), displaying a band of 1304 bp and 535 bp size (Figure 1B). We have also identified the copy number(s) of CyPA-like gene in $P$. indica genome by Southern blotting. There was single gene copy of CyPA-like gene in $P$. indica genome, which resulted in Lane 1 by zero cutters EcoRI and within Lane 2 via single cutter SacI (Figure 1C).

\section{Protein alignment and phylogenetic analysis}

The bioinformatic analysis of $C y P A$-like gene from $P$. indica was performed. Protein sequence of $C y P A$-like gene from $P$. indica and other organisms such as L. bicolor, Homo sapiens, Arabidopsis thaliana, yeast, rice and E. coli were aligned using ClustalW using default parameters. The comparative study of amino acid sequences of PiCyPA was performed using the UniProt BlastP Service (www. uniprot.org/blast/) which revealed 73, 76, 73, 62 and 38\% similarity in L. bicolor, yeast, Arabidopsis, rice and E. coli (Table 1). We found PiCyPA-like gene showing high sequence similarities with cyclophilin representatives from other organisms as shown in Figure 2A. The phylogenetic analysis was also performed and we found $C y P A$ of $P$. indica is closely related to human cyclophilin in respect to high bootstrap value (Figure 2B).

\section{Cloning and characterization of PiCyPA}

The PiCyPA gene was PCR amplified from pBSK-PiCyPA construct using forward: 5 ' CTCGAGCATATGTCCCAG CCCAACGTCTACTTTG $3{ }^{`}$ and reverse: $5{ }^{`}$-GAATTCT TAGACAGTGCCAGACGCAGTAATCTTG 3` primers and resulted PCR product of 535 bp size was cloned into the pGEMT-easy vector (Promega) and then to pET-28a vector (Novagen) by means of NdeI and EcoRI restriction sites, producing the pET-28a-PiCyPA construct (Figure 3A).
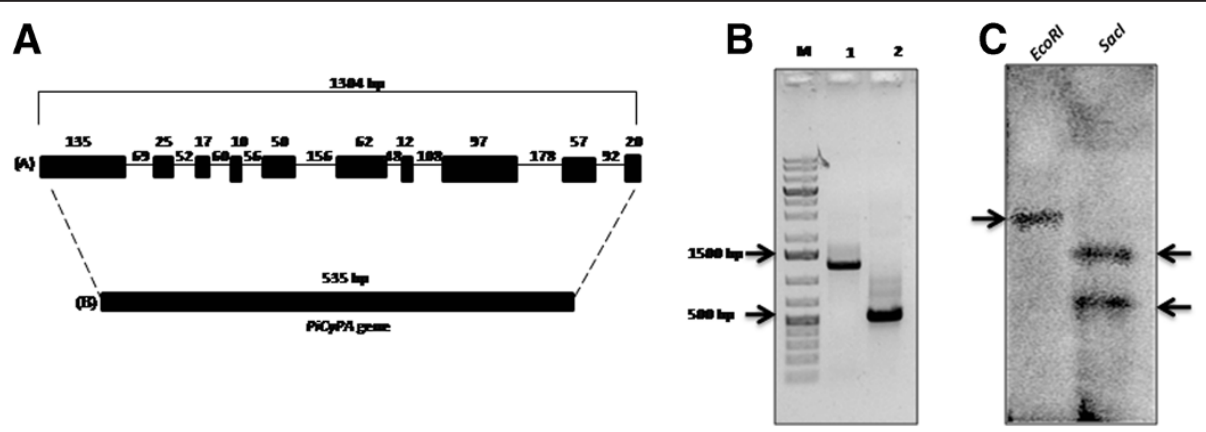

Figure 1 Gnomic organization, PCR- and Southern-profile of CyPA from P. indica. Genomic organization of CyPA gene from $P$. indica containing 10 exons and 9 introns. Introns spliced out and exons joined together and form 495 bp PiCyPA gene (A). Genomic organization of PiCyPA gene confirmed by PCR, lane 1 showing PCR with genomic DNA and lane 2 showing PCR with CDNA (B). Southern blotting confirmed single copy no of PiCyPA gene in lane 1 EcoRl used which is zero cutter and in lane 2 Sacl used which is single cutter of PiCyPA gene (C). 
Table 1 Percentage of similarity between CyPA of $P$. indica and related cyclophilins from other species of fungi, plant and bacteria

\begin{tabular}{lllllll}
\hline Species & UniProt Acc. No. & Gene name & Subcellular location & \% similarity & Putitative length & Putitative function \\
\hline L. bicolor & DS547107 & CPH & Cytosol & $73 \%$ & 162 & Peptidyl-prolyl cis-trans isomerase \\
Yeast & YDR155C & CPR1 & Cytosol & $76 \%$ & 163 & Peptidyl-prolyl cis-trans isomerase \\
Arabidopsis & AT4G38740 & CyPROC1 & Cytosol & $73 \%$ & 172 & Peptidyl-prolyl cis-trans isomerase \\
Rice & LOC_Os05g01270 & CyP & Thylakoid/Plastid & $62 \%$ & 251 & Peptidyl-prolyl cis-trans isomerase \\
E. coli & NC_007946.1 & CyP B & Cellular & $38 \%$ & 164 & Peptidyl-prolyl cis-trans isomerase \\
\hline
\end{tabular}

The PiCyPA gene was expressed in E. coli, inserting a sixhistidine tag onto its $\mathrm{C}$ terminus. The roughly $19-\mathrm{kDa}$ PiCyPA protein was purified close to homogeneity and afterward it was verified by SDS-PAGE analysis (Figure 3B). The distinctiveness of the purified PiCyPA protein was further established by western blot study employing anti-His antibody (Figure 3C). The obtained purified preparation was used to assay the enzyme activity.

\section{Enzymatic activity of the purified PiCyPA protein}

The purified PiCyPA exhibited PPIase enzymatic activity since the first order rate constant $\left(0.104 \mathrm{~s}^{-1}\right)$ in the presence of $1 \mu \mathrm{g}$ of this protein was almost 10-fold higher than the first order rate constant $\left(0.010 \mathrm{~s}^{-1}\right)$ observed for the uncatalysed control (Figure 4A). Further, the first order rate constant in the presence of purified PiCyPA showed an increase with increase in the protein concentration (Figure 4B), thus, implying that the observed PPIase activity was specifically contributed by the PiCyPA. The addition of equal amount of BSA had no significant effect on first order rate constant as compared to the uncatalysed reaction (data not shown). To demonstrate that the purified protein is a true cyclophlin, the PPIase activity of PiCyPA $(1 \mu \mathrm{g})$ was estimated in the presence of FK506 and CsA. It is evident that the PPIase activity of the purified PiCyPA was inhibited dramatically only in the presence of $\mathrm{CsA}$. The presence of $\mathrm{CsA}$ at $3 \mu \mathrm{M}$ concentration resulted in almost $90 \%$ decrease as compared to the uninhibited control (Figure C). Further, inhibition constant was determined in order to determine as to how potent the CsA is as an inhibitor of this PiCyPA. It was observed that the inhibition constant of CsA for inhibition of PiCyPA is $4.435 \mathrm{nM}$. (Figure 4D).

\section{Abiotic stress tolerance in $E$. coli transformed with PiCyPA gene}

PiCyPA overexpression causes E. coli (DH5 $\alpha)$ to tolerate abiotic stresses such as salinity, cold, heat, cadmium

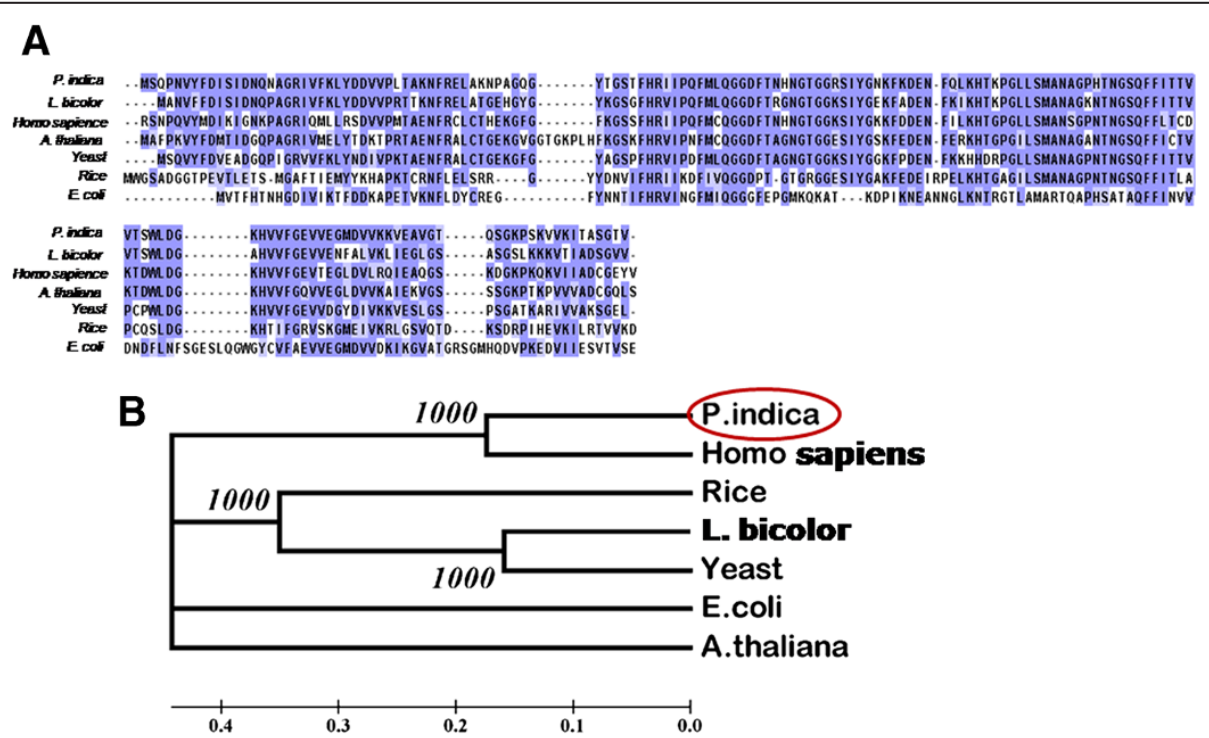

Figure 2 CyPA protein sequence alignment and phylogenetic analysis. Amino acid alignment of CyPA gene from $P$. indica with $L$. bicolor, Homo sapiens, Arabidopsis thaliana, yeast, rice and $E$. coli and its comparison with cyclophilin family. The highly conserved regions of the alignments have been shaded (A). Phylogenetic analysis of P. indica, L. bicolor, Homo sapiens, Arabidopsis thaliana, yeast, rice and E. coli cyclophilin genes was constructed to examine the relationship between the cyclophilin genes in the genomes. The tree was created via neighbor-joining method using 1000 bootstrap replicates. CyP of $P$. indica is closely related to human cyclophilin in respect to high bootstrap value (B). 


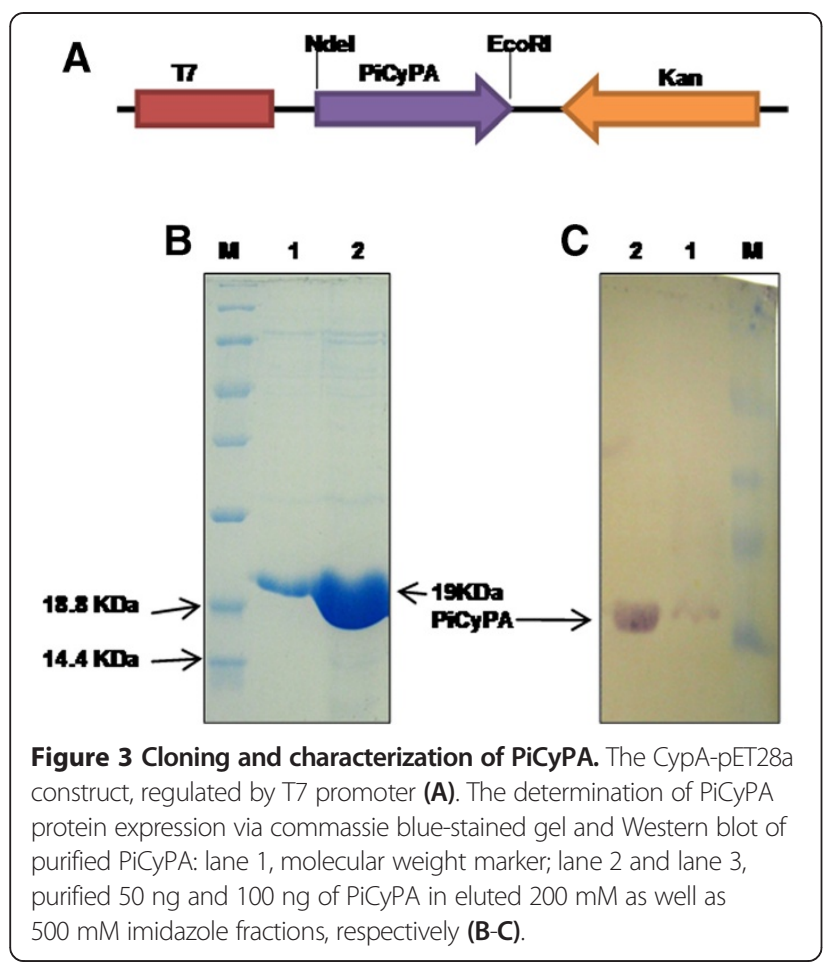

chloride $\left(\mathrm{CdCl}_{2}\right)$, cobalt chloride $\left(\mathrm{CoCl}_{2}\right)$ and hydrogen peroxide $\left(\mathrm{H}_{2} \mathrm{O}_{2}\right)$. The assessment of the PiCypA capability to impart abiotic stress tolerance to bacteria was carried out qualitatively by estimating the $\mathrm{OD}_{600}$ of the bacterial culture as well as quantitatively by estimating turbidity in liquid LB culture medium. Three cultures (i) pET28a-PiCyPA containing E. coli cells plus No salt, (ii) empty pET28a containing $E$. coli cells plus $400 \mathrm{mM}$ $\mathrm{NaCl}$, (iii) pET28a-PiCyPA containing E. coli cells plus $400 \mathrm{mM} \mathrm{NaCl}$ were compared. It showed that an increase in OD of the E. coli cells harbouring pET28aPiCypA was observed under described stress conditions at definite time intervals, although the empty pET28a whose $\mathrm{OD}$ was remained almost stagnant upon stress induction (Figure 5A-F).

\section{Discussion}

Cyclophilins (CyP), generally conserved in all genera together with plants, are playing a part in diverse processes $v i z$., cell division, transcriptional regulation, protein trafficking, cell signaling, pre-mRNA splicing, molecular chaperoning and stress tolerance [22,23]. Here, we identified a new cyclophilin gene (PiCyPA) (Accession No. GQ214003)
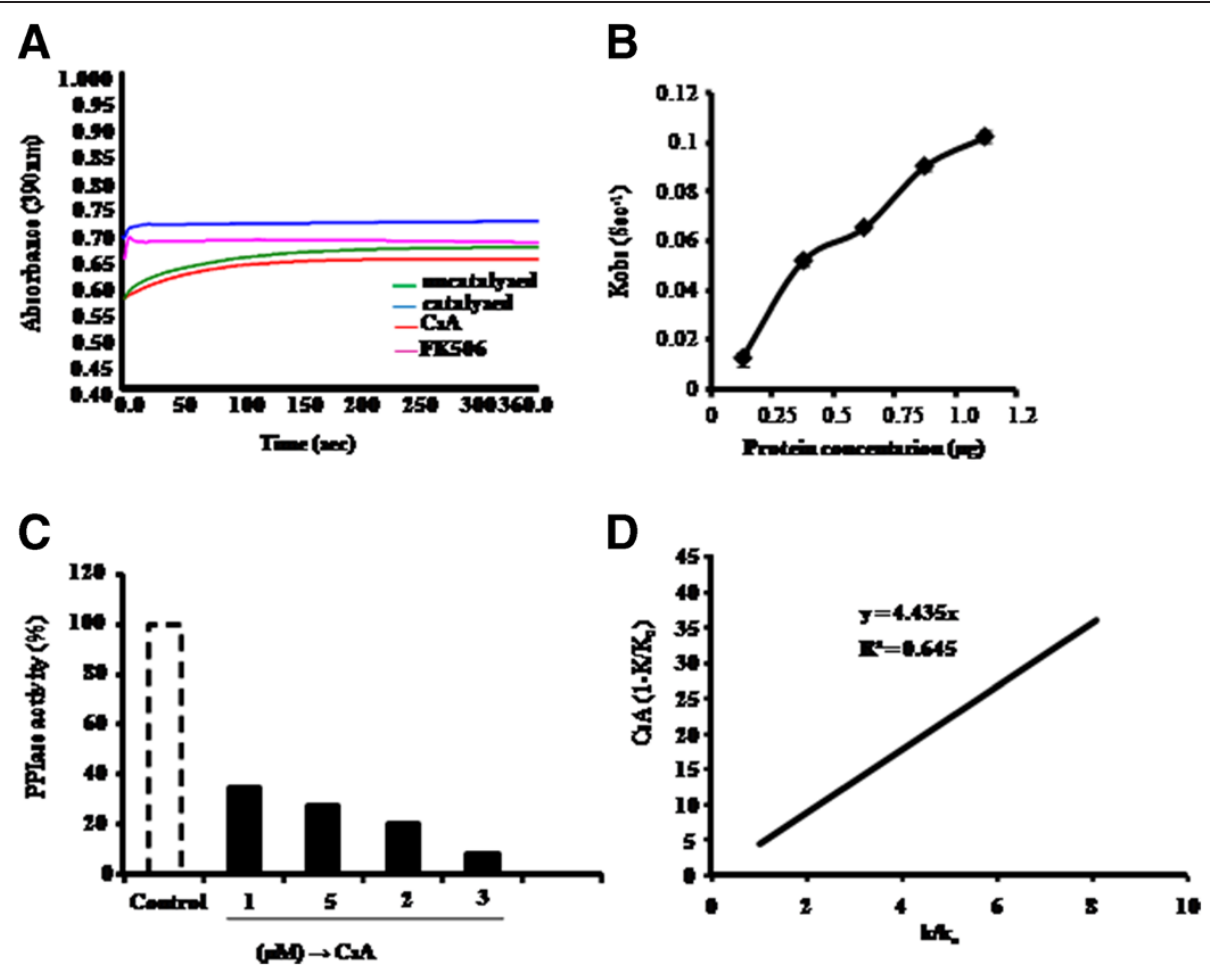

Figure 4 Kinetics of purified PiCyPA cyclophilin. It catalysed hydrolysis of N-succinyl-ala-ala-pro-phe-p-nitroanilidine (peptidyl prolyl cis-trans isomerase or PPlase activity) (A). The dependence of rate constant on the cyclophilin concentration (B). Effect of cyclophilin inhibitor, CsA, on PPlase activity of purified cyclophilin. The data represent the PPlase activity as percent of uninhibited control (C). Determination of inhibition constant of purified CyPA for CSA (D). First order rate constant was analysed using GraFit 4.0 software. Inhibition constant (ki) for CsA was determined as gradient of the line of the best fit from a plot of $[\mathrm{CsA}] /\left(1-k / k_{0}\right)$ against $k / k_{0}$, where $k$ is the rate constant at any given CsA concentration and $k_{0}$ is the rate constant in the absence of CSA. The slope of the line represents the $k_{i}$. Data represent the means SDs of three independent experiments $(n=3)$. 

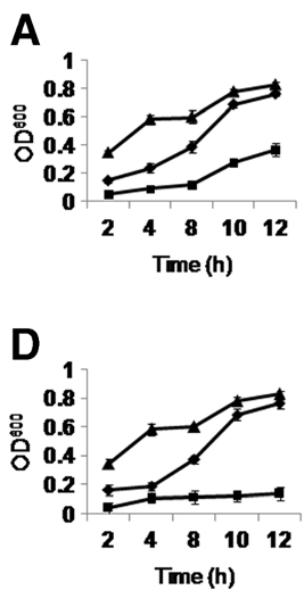
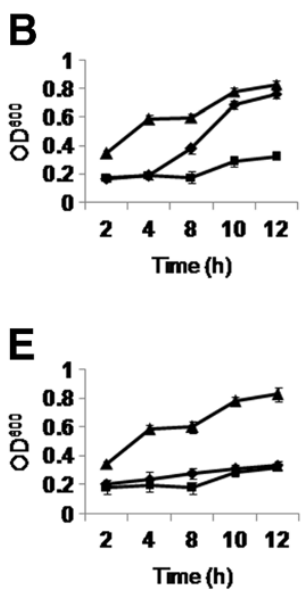
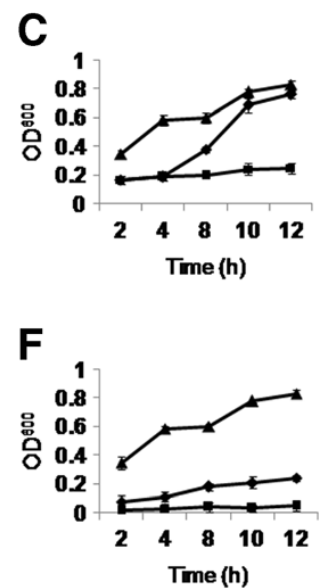

Figure 5 The growth curves of empty pET28a and CyPA-pET28a vector transformed E. coli under different abiotic stresses. The growth curves of CyPA-pET28a transformed E. coli (BL21 codon plus) and empty pET28a vector transformed E. coli showed a gradual drop as a function of different time ( $h$ ) intervals under different abiotic stresses such as salt $(\mathrm{NaCl}, 400 \mathrm{mM})(\mathbf{A})$, cold (B), heat (C), cadmium chloride $\left(\mathrm{CdCl}_{2}, 0.1 \mathrm{mM}\right)$ (D), cobalt chloride $\left(\mathrm{CoCl}_{2}, 1 \mathrm{mM}\right)(\mathbf{E})$ and hydrogen peroxide $\left(\mathrm{H}_{2} \mathrm{O}_{2}, 0.4 \mathrm{mM}\right)(\mathbf{F})$ as compared to no stressed (control). Data represent the means SDs of three independent experiments $(n=3)$. (CyPA-pET28a, No stress; CyPA-pET28a plus stress; Empty pET28a plus stress).

from a root colonizing $P$. indica fungus [24]. Fungal stress signaling pathways have evolved rapidly in a niche-specific fashion that is independent of phylogeny and are relatively well conserved [25]. Hence, the stress response mechanisms reported in case of other fungi might also apply to $P$. indica and the genes responsible might also play similar role [22]. In this study, the PiCyPA encoded protein (Accession No. GQ214003) is highly specific by its PPIas activity and showing differential response against abiotic stresses. Introns are general characteristic of genes of higher eukaryotes. Alternative splicing is a mechanism which greatly enhances the biodiversity of proteins that genome of a particular organism can code for [26]. The genomic organization PiCyPA gene in P. indica genome has been identified via NCBI (http://www.ncbi.nlm.nih.gov), indicating 1304 bp $C y P A$ gene, comprising 10 exons and 9 introns and upon excision of introns it was $535 \mathrm{bp}$ (Figure 1A). The genome organization, biochemistry and molecular biology of the fungus in relative to its mode of action to provide tolerance against abiotic and biotic stress are indeed required to elucidate [27]. Further, a similar trend of genomic organization for PiCyPA gene was evident in PCR products (1304 bp and $535 \mathrm{bp}$ fragments) with $P$. indica gDNA and cDNA (Figure 1B) and Southern profile (Figure 1C). Current data gives us the idea that analogous abiotic stress tolerance genes exist in both lower- and higher-organisms including plants, suggesting that common mechanisms for stress tolerance are emerging across the phylogenetic spectrum [26]. PiCyPA-like gene was indicating sequence similarities with CyP representatives of L. bicolor, Homo sapiens, Arabidopsis thaliana, yeast, rice and E. coli (Figure 2A). We have constructed rooted phylogenetic trees which were bootstrapped with 1000 replicates using MEGA version 5 [28]. It demonstrated that $P$. indica $C y P A$ is closely related to human $C y P$ in respect to high bootstrap value (Figure $2 \mathrm{~B}$ ).

The heterologous expression was observed in E. coli and S. cerevisiae for rice cyclophilin gene (OsCyP2) conferring tolerance to multiple abiotic stresses [29]. Here, $P$. indica cyclophilin gene $(P i C y P A)$ gene was expressed in E. coli and its protein was purified and confirmed (Figure 3A-C). The evaluation of the rate constants of cis-trans isomerization of the peptide free in solution and bound to cyclophilin was categorized earlier. Dissociation of the Michaelis complexes were in similar magnitude as the isomerization rates on the enzymes, contributed steady state parameters [30]. The purified PiCyPA exhibited PPIase enzymatic activity which was 10 -fold higher than the first order rate constant in uncatalysed control (Figure 4A), it increases with increase in the PiCyPA protein concentration (Figure 4B). The inhibition constant (4.435 nM.) of CsA observed for the recombinant PiCyPA is comparable to the inhibition constants observed for other cyclophilins such as fava bean (3.9 $\mathrm{nM})$ [31] and maize (6 nM) [32], but lower than that reported for the human cyclophilins (2-200 nM) [33], thus signifying the variability in sensitivity of different CyPs to CsA. The difference in sensitivity of different CyPs to CsA is in accordance with the earlier reports [34], which demonstrated that PPIase activity of two maize CyPs, TLP40 and TLP20, showed differential sensitivity to inhibition by CsA. It is evident that the PPIase activity of the purified PiCyPA was inhibited dramatically only in the presence of CsA (Figure 4C). The presence of CsA at $3 \mu \mathrm{M}$ concentration resulted 
in almost $90 \%$ decrease as compared to the uninhibited control (Figure 4C). Further, inhibition constant was determined in order to determine as to how potent the CsA, an inhibitor of this PiCyPA. It was observed that the inhibition constant of CsA for inhibition of PiCyPA is 4.435 nM. (Figure 4D).

The role of cyclophilin in abiotic stress tolerance has been well documented in various systems including prokaryotes as well as eukaryotes [29,35-37]. The analysis of transgene also revealed that bacteria expressing the PiCyPA protein could perform much better in multiple abiotic stress conditions as compared to the control. The result was supported by qualitative as well as quantitative data. In the qualitative analysis, the OD of the control samples remained unchanged while the OD of the PiCyPA transgenic bacteria continued to rise. The quantitative estimation analysis in salinity stress condition showed significantly higher growth of PiCyPA expressing bacteria as compared to wild type. These data suggest that the PiCyPA protein is likely to be a part of the general cellular stress response to multiple abiotic stresses which is conserved in prokaryotes, fungus and plants [29,37-39]. The pET28a-PiCyPA transformed bacterial cells showed enhanced tolerance to multiple abiotic stress as compared to empty pET28a vector containing bacterial cells (Figure 5A-F). The present investigation relies on the piece of evidence that the multifunctional PiCyPA embraces assure as a key candidate gene for enhancing abiotic stress tolerance to transgenic plants and recombinant proteins production.

\section{Conclusions}

Our findings ascertain that $P$. indica cyclophilin (PiCyPA) proteins do take a part in a cellular response to mediate various physiological and molecular processes under abiotic stress condition in E. coil. The expression of PiCyPA protein enhanced the transgenic bacterial cells tolerance against wide range of abiotic stresses revealed a positive correlation between PiCyPA and stress response. Presented finding rely on the fact that PiCyPA might be a key player to confer stress tolerance and therefore it may potential hand round as a 'suitable manager for raising transgenic plants tolerance to multiple abiotic stress. Consequently, this study also offers the implication of PiCypA in recombinant proteins production. Further, extended stress conditions do not affect the PiCyPA protein conformation and might be detrimental for protein quality and quantity improvement. Additionally, PiCyPA protein via performing a module in stress signalling net work possibly aid in understanding physiological and molecular processes in relation to stress mitigation. The underlying stress tolerance mechanism in E. coli targeted by $P$. indica cyclophilin (PiCyPA) has not been worked out in plants in best of our knowlege. Further, fine tune insight into the mechanism of stress tolerance potentially mediating via PiCyPA in plants is currently in progress. This novel abiotic stress responsive PiCyPA protein and its future exploitation are indeed required in crop improvements to sustain the productivity under adverse environmental conditions.

\section{Methods}

\section{Identification of CyPA gene of $P$. indica}

Cyclophylin A-like protein (CyPA) (accession number GQ214003) was carefully chosen from cDNA library and its genomic organization CyPA was studied via NCBI (http://www.ncbi.nlm.nih.gov). A cDNA library was constructed from $5 \mu \mathrm{g}$ of poly (A) + RNA (isolated from $P$. indica grown in $0.6 \mathrm{M} \mathrm{NaCl}$ ) in Uni-Zap $\mathrm{XR}$ vector using Zap-cDNA synthesis kit (Stratagene, La Jolla, CA). Using an in vivo excision system the library was converted to phagemids and transferred in SOLR E. coli cells. Plasmids, pBluescript SK- (pBSK) containing cDNA inserts were mass-excised from phage stock of the $P$. indica cDNA library using ExAssist helper phage and propagated in SOLR E. coli cells. The cDNAs of $P$. indica were cloned downstream of the lac promoter of pBSK plasmids thus allowing the expression of recombinant proteins upon isopropyl- $\beta$-D-thiogalactopyranoside (IPTG) induction. Over one million E. coli recombinant cells from the same bacterial culture were plated on LB agar containing $50 \mu \mathrm{g} / \mathrm{ml}$ Kanamycin, $50 \mu \mathrm{g} / \mathrm{ml}$ Ampicillin, $1 \mathrm{mM}$ IPTG and $0.6 \mathrm{M} \mathrm{NaCl}$ (concentration not permissible for the host bacterial growth). As a control the cells were also grown in the above medium with no extra salt included. The plates were incubated at $37^{\circ} \mathrm{C}$ for 12 to $16 \mathrm{hrs}$ as described earlier [40]. 36 bacterial colonies were able to grow on LB plates supplemented with $1 \mathrm{mM}$ IPTG and $0.6 \mathrm{M} \mathrm{NaCl}$ at $37^{\circ} \mathrm{C}$. These colonies were plated on the same medium to confirm their abilities to tolerate high concentration of salt $(0.6 \mathrm{M} \mathrm{NaCl})$. E. coli cells with $\mathrm{pBSK}$ vector were used as negative controls. To further confirm the effective contribution of fungal cDNAs to bacterial $\mathrm{NaCl}$ survival and to exclude any association of the observed phenotype with unpredictable chromosomal mutations, the plasmids were purified from these over-expressing colonies in E. coli SOLR strain and reintroduced into a different $E$. coli strain (DH5 $\alpha)$ and re-plated in LB plates containing IPTG and $0.6 \mathrm{M} \mathrm{NaCl}$. Plasmids from these 36 positive colonies (E.coli $\mathrm{DH} 5 \alpha$ ) were sequenced on both strands by the dideoxy chain termination method, using Sequenase program Version 2.0 (US Biochemicals, Cleveland, $\mathrm{OH}$, USA). The clones of the expression library were found to be in frame with the LacZalfa gene, which is driving expression in pBSK plasmid. Sequences were compared to GenBank database using BLAST N or BLAST X software (http://blast.ncbi.nlm.nih.gov/). One of the clone, 
cyclophylin (accession number GQ214003), was selected for further studies.

\section{Genomic Organization, isolation and substantiation of PiCyPA}

The information of genomic organization of PiCyPA has been taken from contigs sequences of Piriformospora indica submitted in Pubmed (http://www.ncbi.nlm.nih. gov/pubmed/). Genomic organization of PiCyPA has been validated by PCR with gDNA and CDNA using PCR primers (forward: 5` CTCGAGCATATGTCCCAGCCCA ACGTCTACTTTG 3` and reverse: $5^{`}$-GAATTCTTAGAC AGTGCCAGACGCAGTAATCTTG 3`), respectively. Further $P i C y P A$ gene copy numbers have been validated by southern blotting via standard protocol.

\section{Phylogenetic analysis}

Protein sequences of cyclophilins (CyP) from different representative organisms were downloaded from NCBI database. These CyP sequences were aligned by means of ClustalW using default parameters. Phylogenetic analysis was accomplished using MEGA version 5 [41]. To build phylogenies, neighbour joining method [42] was employed and bootstrap analysis was performed by means of 1000 replicates. The phylogram was rooted using distantly related $\mathrm{CyP}$ sequences of different organisms.

\section{Cloning of PiCyPA gene into the pET28a expression vector} The entire sequence of cyclophilin gene, cloned into pBSK vector was amplified by using PCR primers (forward: $5 `$ CTCGAGCATATGTCCCAGCCCAACGTCTA CTTTG 3` and reverse: $5^{`}$-GAATTCTTAGACAGTG CCAGACGCAGTAATCTTG 3`). The PCR product was subsequently cloned into the pGEMT-easy vector (Promega) and it was sequenced using the T7 and SP6 primers respectively. After that it was subcloned into the pET-28a vector (Novagen) using the NdeI and EcoRI restriction sites to generate the pET-28a-PiCyp A construct for further characterization of cyclophilin protein.

\section{Protein expression and Purification}

pET28a-PiCyPA construct was transformed into E. coli BL21 (DE3) codon plus cells. Transformed cells were grown in $\mathrm{LB}$ medium at $37^{\circ} \mathrm{C}$ with continuous shaking as $175 \mathrm{rpm}$. Culture was induced at $\mathrm{OD}_{600} \sim 0.8$ using $0.5 \mathrm{mM}$ IPTG at $18^{\circ} \mathrm{C}$ for overnight. Cells were harvested by centrifugation at $5000 \mathrm{~g}$ for $20 \mathrm{~min}$ and the protein was induced and purified using Ni-NTA (Qiagen, http:// www.qiagen.com) resin and standard protocols. The protein was checked for purity by SDS-PAGE [10\% (w/v) polyacrylamide gel] and commassie staining.

\section{Western blot analysis}

The protein analysis was made by SDS-PAGE and transferred electrophoretically to nitrocellulose membrane by means of standard method. Subsequent to blocking, the membrane was developed with the suitable primary antibody (Penta-His; Qiagen) at defined period of $3 \mathrm{~h}$ at $27^{\circ} \mathrm{C}$. The blot was then raised with the appropriate secondary antibody linked to alkaline phosphatase (SigmaAldrich, http://www.sigmaaldrich.com) and then developed via the standard method.

\section{Peptidyl prolyl cis-trans isomerase (PPlase) assay}

PPIase activity was assayed at $15^{\circ} \mathrm{C}$ for $360 \mathrm{~s}$ in a coupled reaction with chymotrypsin as described earlier [42]. The one $\mathrm{ml}$ assay mixture contained $40 \mu \mathrm{M}$ N-succinylala ala-pro-phep- nitroanilidine as test peptide, assay buffer [50 mM HEPES (pH 8.0), $150 \mathrm{mM} \mathrm{NaCl}$, $0.05 \%$ Triton $\mathrm{X}-100$ ] and $30-50 \mu \mathrm{g}$ of total proteins. The reaction was initiated by the addition of chymotrypsin $(300 \mu \mathrm{g} / \mathrm{ml})$ and the change in absorbance at $390 \mathrm{~nm}$ was monitored using a spectrophotometer (Perkin-Elmer Lambda Bio20) equipped with a Peltier temperature control system. The effect of FK506 and cyclosporine A (CsA), which are specific inhibitors of PPIase activity associated with FK506-binding proteins (FKBPs)- and cyclophilins was estimated by the addition of inhibitors to the assay mix $30 \mathrm{~min}$ before the start of the reaction, which followed by an incubation at $4^{\circ} \mathrm{C}$. The PPIase activity was calculated as the product of the difference in the catalysed and uncatalysed first order rate constants (derived from the kinetics of the absorbance change at $390 \mathrm{~nm}$ ) and the amount of substrate in each reaction [43].

\section{Growth of E. coli bacteria transformed with PiCyPA gene under abiotic stresses}

The E. coli (BL21 codon plus cells) were transformed with PiCyp-pET28 and empty pET28a with the standard method. The transformed BL21 codon plus cells were first allowed to grow to log phase OD600 $=0.5$. The equal amount of these cells were transferred to sterile culture tubes with $10 \mathrm{ml}$ of LB medium containing $50 \mu \mathrm{g} / \mathrm{ml}$ kanamycin, $1 \mathrm{mM}$ IPTG (final concentration) and $400 \mathrm{mM}$ $\mathrm{NaCl}$ (final concentration). The cells were allowed to grow at $37^{\circ} \mathrm{C}$ and the growth was monitored by taking the OD600 at the interval of $2 \mathrm{~h}$. For other stresses, the overnight grown BL21 codon plus cells in a LB medium were then cultured until the mid-log phase and then incubated it for an additional $2 \mathrm{~h}$ after $0.2 \mathrm{mM}$ IPTG treatment with consistent shaking under different stresses like cold, heat, $0.2 \mathrm{mM} \mathrm{CdCl}_{2}, 1 \mathrm{mM} \mathrm{CoCl}_{2}$, $0.4 \mathrm{mM} \mathrm{H}_{2} \mathrm{O}_{2}$. 


\section{Abbreviations}

cDNA: Complementary DNA; bp: Base pairs; PPlase: Peptidyl prolyl isomerase; CsA: Cyclosporin A; Nm: Nano molar; NCBI: National center for biotechnology information; gDNA: Genomic DNA; PCR: Polymerase chain reaction; kDa: Kilodaltons; SDS-PAGE: Sodium dodecyl sulfate polyacrylamide gel electrophoresis; His: Histidine; $S^{-1}$ : Per second; BSA: Bovine serum albumin; $\mu \mathrm{g}$ : micro gram; $\mu \mathrm{M}$ : micro molar; $\mathrm{CdCl}_{2}$ : Cadmium chloride; $\mathrm{CoCl}_{2}$ : Cobalt chloride; $\mathrm{H}_{2} \mathrm{O}_{2}$ : Hydrogen peroxide; OD: Optical density; mRNA: Messenger RNA.

\section{Competing interests}

The authors have declared that no competing interests exist.

\section{Authors' contributions}

DKT carried out the molecular study of cyclophilin A like protein from $P$. indica (PiCyPA) and participated in its genomic organization, identification, isolation, molecular characterization and sequence alignment, cloning into the pET28a expression vector, western blot analysis and its expression in E.coli ess. TD performed the prolyl cis-trans isomerase (PPlase) assay. MWA coordinated with the experiments on biotic stress tolerance in $E$. coli and performed data analysis, interpreted the results and drafted the manuscript. PS desined the enzyme kinetics assay, performed the analysis of data, and interpreted the results. NT conceived of the study and designed the experiments. All authors read and approved the final manuscript.

\section{Acknowledgments}

Work on signal transduction and plant stress signaling in NT's laboratory is partially supported by Department of Science and Technology (DST) and Department of Biotechnology (DBT), Government of India. Government of India. D.K.T. is grateful to Department of Biotechnology (DBT) for PhD fellowship.

\section{Author details}

'Plant Molecular Biology Group, International Centre for Genetic Engineering and Biotechnology (ICGEB), Aruna Asaf Ali Marg, New Delhi 110 067, India. 2Department of Biotechnology, Guru Nanak Dev University, Amritsar 143 005, Punjab, India.

Received: 29 October 2013 Accepted: 19 December 2013

Published: 23 December 2013

\section{References}

1. Tuteja N: Abscisic acid and abiotic stress signalling. Plant Signal Behav 2007, 2:135-8

2. Verma S, Varma A, Rexer KH, Hassel A, Kost G, Sarbhoy A, Bisen P, Bütehorn B, Franken P: Piriformospora indica, gen. et sp. nov., a new root-colonizing fungus. Mycologia 1998, 90:896-903.

3. Waller F, Achatz B, Baltruschat H, Fodor J, Becker K, Fischer M, Heier T, Hu'ckelhoven R, Neumann C, Wettstein DV, Franken P, Kogel K: The endophytic fungus Piriformospora indica reprograms barley to salt-stress tolerance, disease resistance, and higher yield. Proc Natl Acad Sci USA 2005, 102:13386-13391.

4. Das A, Kamal S, Shakil NA, Sherameti I, Oelmüller R, Dua M, Tuteja N, Johri AK, Varma A: The root endophyte fungus Piriformospora indica leads to early flowering, higher biomass and altered secondary metabolites of the medicinal plant, Coleus forskohlii. Plant Signal Behav 2012, 7:103-112.

5. Wang P, Heitman J: The cyclophilins. Genome Biol 2005, 6:226.

6. Schreiber SL: Chemistry and biology of the immunophilins and their immunosuppressive ligands. Science 1991, 251:283-287.

7. Shaw PE: Peptidyl-prolyl isomerases: a new twist to transcription. EMBO Rep 2002, 3:521-526.

8. Price ER, Jin M, Lim D, Pati S, Walsh CT, McKeon FD: Cyclophilin B trafficking through the secretory pathway is altered by binding of cyclosporin. Proc Natl Acad Sci USA 1994, 91:3931-3935.

9. Freeman BC, Toft DO, Morimoto Rl: Molecular chaperone machines: chaperone activities of the cyclophilin Cyp-40 and the steroid aporeceptor-associated protein p23. Science 1996, 274:1718-1720.

10. Duina AA, Chang HC, Marsh JA, Lindquist S, Gaber RF: A cyclophilin function in Hsp90-dependent signal transduction. Science 1996, 274:1713-1715.

11. Horowitz DS, Lee EJ, Mabon SA, Misteli T: A cyclophilin functions in pre-mRNA splicing. EMBO J 2002, 21:470-480.
12. Schmid FX: Prolyl isomerase: enzymatic catalysis of slow protein-folding reactions. Annu Rev Biophys Biomol Struct 1993, 22:123-142.

13. Weisman R, Creanor J, Fantes P: A multicopy suppressor of a cell cycle defect in $\mathrm{S}$. pombe encodes a heat shock-inducible $40 \mathrm{kDa}$ cyclophilin-like protein. EMBO J 1996, 15:447-456

14. Andreeva L, Heads R, Green CJ: Cyclophilins and their possible role in the stress response. Int J Exp Pathol 1999, 80:305-315.

15. Dominguez-Solis JR, He Z, Lima A, Ting J, Buchanan BB, Luan S: A cyclophilin links redox and light signals to cysteine biosynthesis and stress responses in chloroplasts. Proc Natl Acad Sci USA 2008, 105:16386-16391.

16. Takahashi N, Hayano T, Suzuki M: Peptidyl-prolyl cis-trans isomerase is the cyclosporin A-binding protein cyclophilin. Nature 1989, 337:473-475.

17. Göthel SF, Herrler M, Marahiel MA: Peptidyl-prolyl cis-trans isomerase of Bacillus subtilis: identification of residues involved in cyclosporin A affinity and catalytic efficiency. Biochemistry 1996, 35:3636-3640.

18. Davis TL, Walker JR, Campagna-Slater V, Finerty PJ Jr, Paramanathan R, Bernstein G, Mackenzie F, Tempel W, Ouyang H, Lee WH, Eisenmesser EZ, Dhe-Paganon S: Structural and biochemical characterization of the human cyclophilin family of peptidyl-prolyl isomerases. PLoS Biol 2010, 8:e1000439.

19. Handschumacher RE, Harding MW, Rice J, Drugge RJ, Speicher DW: Cyclophilin: a specific cytosolic binding protein for cyclosporin A. Science 1984, 226:544-547.

20. Liu J, Farmer JD, Lane WS, Friedman J, Weissman I, Schreiber SL: Calcineurin is a common target of cyclophilin-cyclosporin A and FKBP-FK506 complexes. Cell 1991, 66:807-815.

21. Xiong L, Schumaker KS, Zhu J: Cell signaling during cold, drought, and salt stress. Plant Cell 2002, 14:165-183.

22. Trivedi DK, Ansari MW, Tuteja N: Multiple abiotic stress responsive rice cyclophilin (OsCYP-25) mediates a wide range of cellular responses. Commun Integr Biol 2013, 6:e25260.

23. Ruan SL, Ma HS, Wang SH, Fu YP, Xin Y, Liu WZ, Wang F, Tong JX, Wang SZ, Chen $\mathrm{HZ}$ : Proteomic identification of OsCYP2, a rice cyclophilin that confers salt tolerance in rice (Oryza sativa L.) seedlings when overexpressed. BMC Plant Biol 2011, 11:34.

24. Franken P: The plant strengthening root endophyte Piriformospora indica: potential application and the biology behind. Appl Microbiol Biotechnol 2012, 96:1455-1464.

25. Nikolaou E, Agrafioti I, Stumpf M, Quinn J, Stansfield I, Brown AJ: Phylogenetic diversity of stress signalling pathways in fungi. BMC Evol Biol 2009, 9:44.

26. Vaid N, Pandey PK, Tuteja N: Genome-wide analysis of lectin receptor-like kinase family from Arabidopsis and rice. Plant Mol Biol 2012, 80:365-388.

27. Trivedi DK, Yadav S, Vaid N, Tuteja N: Genome wide analysis of Cyclophilin gene family from rice and Arabidopsis and its comparison with yeast. Plant Signal Behav 2012, 7:1653-66.

28. Tamura K, Peterson D, Peterson N, Stecher G, Nei M, Kumar S: MEGA5: molecular evolutionary genetics analysis using maximum likelihood, evolutionary distance, and maximum parsimony methods. Mol Biol Evol 2011, 28:2731-2739.

29. Kumari S, Singh P, Singla-Pareek SL, Pareek A: Heterologous expression of a salinity and developmentally regulated rice cyclophilin gene (OsCyp2) in E. coli and S. cerevisiae confers tolerance towards multiple abiotic stresses. Mol Biotechnol 2009, 42:195-204.

30. Kern D, Kern G, Scherer G, Fischer G, Drakenberg T: Kinetic analysis of cyclophilin-catalyzed prolyl cis/trans isomerization by dynamic NMR spectroscopy. Biochemistry 1995, 34:13594-602.

31. Luan S, Albers MW, Schreiber SL: Light-regulated, tissue-specific immunophilins in a higher plant. Proc Natl Acad Sci USA 1994, 91:984-988.

32. Sheldon PS, Venis MA: Purification and characterization of cytosolic and microsomal cyclophilins from maize (Zea mays). Biochem J 1996, 315:965-970

33. Kofron JL, KuzmiE P, Kishore V, Colon-Bonilla E, Rich DH: Determination of kinetic constants for peptidyl-prolyl cis-trans isomerases by an improved spectrophotometric assay. Biochemistry 1991, 30:6127-6134.

34. Edvardsson A, Eshaghi S, Vener AV, Andersson B: The major peptidyl-prolyl isomerase activity in thylakoid lumen of plant chloroplasts belongs to a novel cyclophilin TLP20. FEBS Lett 2003, 542:137-141.

35. Sekhar K, Priyanka B, Reddy VD, Rao KV: Isolation and characterization of a pigeonpea cyclophilin (CcCYP) gene, and its over-expression in Arabidopsis confers multiple abiotic stress tolerance. Plant Cell Environ 2010, 33:1324-1338. 
36. Ruan SL, Ma HS, Wang SH, Fu YP, Xin Y, Liu WZ, Wang F, Tong ZX, Wang SZ, Chen HZ: Proteomic identification of OsCYP2, a rice cyclophilin that confers salt tolerance in rice (Oryza sativa L.) seedlings when overexpressed. BMC Plant Biol 2011. doi:10.1186/1471-2229-11-34.

37. Kim S-K, You NM, Park JC, Joung Y, Kim B-G, Ahn JC, Cho HS: The rice thylakoid lumenal cyclophilin OsCYP20-2 confers enhanced environmental stress tolerance in tobacco and Arabidopsis. Plant Cell Rep 2012, 31:417-426.

38. Kultz D: Molecular and evolutionary basis of the cellular stress response. Ann Rev Physiol 2003, 67:225-257.

39. Tajrishi MM, Vaid N, Tuteja R, Tuteja N: Overexpression of a pea DNA helicase 45 in bacteria confers salinity stress tolerance. Plant Signal Behav 2011, 6:1271-1275

40. Joshi A, Dang HQ, Vaid N, Tuteja N: Isolation of high salinity stress tolerant genes from Pisum sativum by random overexpression in Escherichia coli and their functional validation. Plant Signal Behav 2009, 4:400-412.

41. Saitou N, Nei M: The neighbor-joining method: a new method for reconstructing phylogenetic trees. Mol Biol Evol 1987, 4:406-425.

42. Fischer $\mathrm{G}$, Bang $\mathrm{H}$, Mech $\mathrm{C}$ : Determination of enzymatic catalysis for the cis-trans-isomerization of peptide binding in proline-containing peptides. Biomed Biochim Acta 1984, 43:1101-1111.

43. Breiman A, Fawcett TW, Ghirardi ML, Mattoo AK: Plant organelles contain distinct peptidylprolyl cis-trans-isomerases. J Biol Chem 1992, 267:21293-21296.

doi:10.1186/1756-0500-6-555

Cite this article as: Trivedi et al:: Molecular characterization of cyclophilin A-like protein from Piriformospora indica for its potential role to abiotic stress tolerance in E. coli. BMC Research Notes 2013 6:555.

\section{Submit your next manuscript to BioMed Central and take full advantage of:}

- Convenient online submission

- Thorough peer review

- No space constraints or color figure charges

- Immediate publication on acceptance

- Inclusion in PubMed, CAS, Scopus and Google Scholar

- Research which is freely available for redistribution 